\title{
Ggnbp2-Null Mutation in Mice Leads to Male Infertility due to a Defect at the Spermiogenesis Stage
}

Lingyun Liu, ${ }^{*}$ Yan He, ${ }^{\dagger}$ Kaimin Guo, ${ }^{*}$ Linying Zhou, ${ }^{\dagger}$ Xian $\mathrm{Li}^{\dagger}{ }^{\dagger}$ Michael Tseng, ${ }^{\dagger} \mathrm{Lu} \mathrm{Cai},{ }^{\S} \mathrm{Zi}-J i a n$ Lan, ${ }^{\top}$ Junmei Zhou, Hongliang Wang, ${ }^{*}$ and Zhenmin Lei ${ }^{\dagger}$

From the Department of Andrology, * The First Hospital of Jilin University, Changchun, China; the Departments of Obstetrics, Gynecology and Women's Health, ${ }^{\dagger}$ Anatomical Sciences and Neurobiology, ${ }^{\ddagger}$ and Pediatrics, ${ }^{\S}$ University of Louisville School of Medicine, Louisville, Kentucky; the Division of Life Sciences and Center for Nutrigenomics and Applied Animal Nutrition, "Alltech Inc., Nicholasville, Kentucky; and the Central Laboratory," Shanghai Children's Hospital, Shanghai Jiao Tong University, Shanghai, China

Accepted for publication July 20, 2017.

Address correspondence to Zhenmin Lei, M.D., Ph.D. Department of Obstetrics/Gy naecology, University of Louisville Health Sciences Center, 412 A Bldg, $500 \mathrm{~S}$ Preston St, Louisville, KY 40202; or Hongliang Wang, M.D., Department of Andrology, The First Hospital of Jilin University, Changchun, Jilin 130021, China. E-mail: zhenmin.lei@louisville.edu or whl1228@126.com.

\begin{abstract}
Gametogenetin binding protein 2 (GGNBP2) is an evolutionarily conserved zinc finger protein. Although Ggnbp2-null embryos in the B6 background died because of a defective placenta, $6.8 \%$ of Ggnbp2-null mice in the B6/129 mixed background were viable and continued to adulthood. Adult Ggnbp2-null males were sterile, with smaller testes and an azoospermic phenotype, whereas mutant females were fertile. Histopathological analysis of 2-month-old Ggnbp2-null testes revealed absence of mature spermatozoa in the seminiferous tubules and epididymides and reduction of the number of spermatids. Ultrastructural analysis indicated dramatic morphological defects of developing spermatids in the Ggnbp2-null testes, including irregularly shaped acrosomes, acrosome detachment, cytoplasmic remnant, ectopic manchette, and ill-formed head shape in both elongating and elongated spermatids. However, the numbers of spermatogonia, spermatocytes, Leydig cells, and Sertoli cells in Ggnbp2-null testes did not significantly differ from the wild-type siblings. Gonadotropins, testosterone, and the blood-testis barrier were essentially unaffected. Western blot analyses showed increases in $\alpha$-E-catenin, $\beta$-catenin, and $\mathrm{N}$-cadherin, decreases in E-cadherin, afadin, and nectin-3, and no changes in vinculin, nectin-2, focal adhesion kinase, and integrin- $\beta 1$ protein levels in Ggnbp2-null testes compared to wild-type siblings. Together, this study demonstrates that GGNBP2 is critically required for maintenance of the adhesion integrity of the adlumenal germ epithelium and is indispensable for normal spermatid transformation into mature spermatozoa in mice. (Am J Pathol 2017, 187: 2508-2519; http://dx.doi.org/10.1016/j.ajpath.2017.07.016)
\end{abstract}

Mammalian male fertility requires sufficient numbers of morphological normal and motile sperm that is generated through a highly organized cyclic process known as spermatogenesis. Spermatogenesis originated from diploid spermatogonial multiplication, followed by two successive meiotic reductive divisions to produce haploid round spermatids; round spermatids finally undergo a complex cytodifferentiation process called spermiogenesis to become motile spermatozoa. ${ }^{1,2}$ During the spermiogenic phase, drastic morphological changes take place to transform circular spermatids into spermatozoa, which include progressive elongation, acrosomal and flagellar formation, nuclear condensation, and dramatic cytoplasmic remodeling.
Extensive studies suggest that this remarkable cellular differentiation process is elaborately regulated by a battery of male germ cell-specific genes estimated to be approximately 600 to $1000 .^{3,4}$ Mouse gene-knockout studies in the past two decades have demonstrated that $>40$ genes are essential for normal spermiogenesis., ${ }^{5,6}$ These represent a few well-established genes that participate in spermiogenesis; many more need to be identified.

Supported in part by NIH grants R01-HD057501 (Z.L.), 5P20RR017702-10, and 8P20 GM103453-10, and project I (Z.-J.L.).

Diclosures: None declared.

Current address of Y.H. and L.Z., Fujian Medical University, Fuzhou, China. 
Gametogenetin binding protein 2 (GGNBP2) is encoded by a gene consisting of 15 exons. It is highly conserved across humans, rats, and mice, sharing $87 \%$ homology in nucleotide sequence and 96\% homology in amino acid sequence between humans and mice. The full-length murine GGNBP2 protein is composed of 740 amino acids. It contains a Cys2His2 zinc finger motif at the $\mathrm{N}$ terminus and is also named zinc finger protein 403 (ZFP403 or ZNF403). ${ }^{7-10}$ A shorter form of GGNBP2, previously called laryngeal carcinoma-related protein 1 , was reported to be dramatically down-regulated in primary laryngeal carcinomas, drug-resistant ovarian cancers, and several human cancer cell lines. ${ }^{11-14}$ It has been speculated that GGNBP2 might play a role in regulation of tumorigenesis. Overexpression of human GGNBP2 in a hepatic cancer cell line inhibited cell growth, proliferation, and migration. ${ }^{12}$ GGNBP2 knockdown, on the other hand, resulted in $\mathrm{G}_{2} / \mathrm{M}$ cell cycle arrest. ${ }^{15}$ Recent studies demonstrated that GGNBP2 acted as a tumor suppressor in human estrogen receptor $\alpha$-positive breast cancer cell lines by its activity in the impediment of tumorigenicity in nude mice. ${ }^{16}$

Ggnbp2 was initially identified as a dioxin-induced factor 3 in mouse embryonic stem cells in $2001 .^{7}$ The murine Ggnbp2 is in chromosome 11, which is known to contain several important reproductive-related genetic loci. For example, mutation of the 11A2-3 locus and targeted disruptions of Ube $2 b$ or Ace-T led to male infertility. ${ }^{17}$ Ggnbp 2 is abundantly expressed in the testis during spermatogenesis in adult testes, and the protein was predominately localized in spermatocytes and round spermatids. ${ }^{7}$ Further study revealed that GGNBP2 was one of the several proteins that interact with a testicular protein, gametogenetin $(\mathrm{GGN}) .{ }^{8}$ GGNBP2 is hence postulated to play a role in spermatogenesis. To elucidate the function of GGNBP2 in vivo, we generated a Ggnbp2 knockout mouse line. Ggnbp2-null embryos in the B6 background died because of a defective placenta. ${ }^{10}$ A portion of Ggnbp2-null mice on the B6/129 mixed background were viable and continued to adulthood. Adult Ggnbp2-null males were sterile, with smaller testes and an azoospermic phenotype, whereas mutant females were fertile. Loss of Ggnbp2 resulted in a severe impairment of spermiogenesis that eventually led to male infertility. This study, for the first time, demonstrates that GGNBP2 is critically required for maintenance of the adhesion integrity of the adlumenal germ epithelium and is indispensable for normal spermatid transformation into mature spermatozoa in mice.

\section{Materials and Methods}

\section{Animals}

Ggnbp2 knockout (Ggnbp2KO) heterozygous female mice with the C57BL/6 background were crossed with wild-type (WT) male mice with the $129 / \mathrm{Sv}$ background, and then these Ggnbp2 heterozygous males and females with the mixed background were bred. Animal genotyping was performed by PCR, as described previously, with genomic DNA isolated from tail clips of mice. ${ }^{18}$ The PCR primers are listed in Table 1. For a fertility test, six 2-month-old Ggnbp2-null and WT male mice were mated with proven fertile females (one male/one female per cage) for 6 months. The number of pups produced from each female was recorded, as described previously. ${ }^{18}$ All of the mice were raised under standard laboratory conditions, with a 12-hour light/ dark cycle and free access to food and water. Mice were euthanized under ketamine anesthesia for tissue and blood collections, and efforts were made to minimize their discomfort. The studies have been approved by the Animal Care and Use Committee of the University of Louisville (Louisville, KY).

\section{RT-PCR and Real-Time Quantitative PCR}

Total RNA was extracted from the testes using Trizol reagent (Invitrogen, Waltham, MA), according to the manufacturer's instructions. Total RNA $(2 \mu \mathrm{g})$ was reverse transcribed into cDNA with random primers (Invitrogen) and Avian Myeloblastosis Virus Reverse Transcriptase (Promega Corp., Madison, WI). Testicular Ggnbp2 expression during postnatal development was detected by real-time quantitative PCR, performed with SYBR Green reagents kits (Invitrogen) using the StepOnePlus real-time PCR system (Applied Biosystems, Waltham, MA). The real-time PCR steps included holding at $50^{\circ} \mathrm{C}$ for 2 minutes and $95^{\circ} \mathrm{C}$ for 2 minutes, followed by repeated 40 cycles of $95^{\circ} \mathrm{C}$ for 15 seconds, $60^{\circ} \mathrm{C}$ for 15 seconds, and $72^{\circ} \mathrm{C}$ for 60 seconds. The relative expression levels of Ggnbp2 were calculated by the comparative $\Delta \Delta \mathrm{Ct} \operatorname{method}^{19}$ and normalized to a housekeeping gene, glyceraldehyde 3-phosphate dehydrogenase (Gapdh).

For RT-PCR, the cDNA was amplified with Ggnbp2 and Gapdh primers. Each PCR cycle consisted of denaturation for 45 seconds at $94^{\circ} \mathrm{C}$, annealing for 1 minute at $57^{\circ} \mathrm{C}$, and extension for 1 minute at $72^{\circ} \mathrm{C}$. The amplified products were separated by electrophoresis in agarose gels and stained by ethidium bromide.

Real-time quantitative PCR and RT-PCR primers, as listed in Table 1, were designed according to the sequences obtained from GenBank and synthesized by Operon Technologies (Alameda, CA).

\section{mRNA in Situ Hybridization}

Formalin-fixed, paraffin-embedded testicular tissue sections (5 $\mu \mathrm{m}$ thick) were processed for Ggnbp2 mRNA in situ detection using the RNAscope 2.0 formalin-fixed, paraffinembedded fast red detection kit (Advanced Cell Diagnostics, Hayward, CA), according to the manufacturer's recommended procedures. Briefly, the sections were deparaffinized and boiled with a pretreatment buffer for 15 minutes. After being rinsed with distilled water, the sections were incubated at $40^{\circ} \mathrm{C}$ with murine Ggnbp2 RNAscope 
Table 1 Primer Sequences for Genotyping and Semiquantitative RT-PCR

\begin{tabular}{lll}
\hline Gene & Primer sequence & PCR cycles \\
\hline Ggnbp2 (genotyping) & F: 5'-AGTGCCATTTACCCACCAAG-3' & 30 \\
Ggnbp2 (qPCR) & R: 5'-GAAAGGAGGAGGGAAAGGAA-3' & \\
& F: 5'-CCTTCGAGAGGAGGCAGATCC-3' & 40 \\
Gapdh (qPCR) & R: 5'-AACTGCTTTAGTTGTGCACCATTAT-3' \\
& F: 5'-CTGGAGAAACCTGCCAAGTA-3' & \\
Ggnbp2 (RT-PCR) & R: 5'-TGTTGCTGTAGCCGTATTCA-3' & 30 \\
Gapdh (RT-PCR) & F: 5'-CTCATTGGTGAACTTGACTGC-3' & 30 \\
& R: 5'-TCACTGCTTTCTCGTCTGCGGTG-3' & 30 \\
\hline
\end{tabular}

$F$, forward primer; $q P C R$, real-time quantitative $P C R ; R$, reverse primer.

probes, followed by a colorimetric reaction with fast red to visualize the hybridized signal. Then, sections were counterstained with hematoxylin, dehydrated, and mounted. To control for background, we used a negative control probe against the Bacillus subtilis dihydrodipicolinate reductase, dapB (Advanced Cell Diagnostics). All sections were observed and imaged with a bright-field Olympus microscope (model IX71/DP72; Olympus, Tokyo, Japan).

\section{Immunohistochemical Staining}

The testes were fixed with $10 \%$ formalin and embedded in paraffin. The immunostaining procedure was performed by an avidin-biotin immunoperoxidase method. Briefly, deparaffinized sections were rehydrated and then incubated with hydrogen peroxide. The sections were then incubated with the primary antibodies, as listed in Table 2 , at $4{ }^{\circ} \mathrm{C}$ overnight and then incubated with biotinylated secondary antibody (1:100; Vector Laboratories, Burlingame, CA).
After rinsing with phosphate-buffered saline (PBS), sections were incubated with an avidin-biotin-horseradish peroxidase complex using a Vectastain ABC kit (Vector Laboratories). Immunostaining was detected by incubation of the sections with the substrate 3'3-diaminobenzidine. All sections were counterstained with hematoxylin. Replacement of the primary antibody with irrelevant rabbit or mouse IgG was used as a procedure control.

\section{Periodic Acid-Schiff Staining}

The testes were fixed with $10 \%$ formalin and embedded in paraffin. Deparaffinized and rehydrated sections were incubated with periodic acid solution (Sigma-Aldrich, St. Louis, MO) for 5 minutes at room temperature and rinsed in distilled water. Sections were immersed in Schiff's reagent for 15 minutes at room temperature. After washing with distilled water for 5 minutes, the sections were counterstained with hematoxylin solution for 90 seconds.

Table 2 Antibodies Used in This Report

\begin{tabular}{|c|c|c|c|c|c|}
\hline Antibody & Host species & Vendor & Catalog no. & Application & Dilution \\
\hline GGNBP2 & Rabbit & Pacific Immunology Corp. (Ramona, CA) & PAC-139 & IHC & 1:1500 \\
\hline Cldauin-11 & Mouse & Santa Cruz Biotechnology (Dallas, TX) & SC-9412 & IF & $1: 400$ \\
\hline SALL4 & Mouse & Sigma-Aldrich & B8434 & IF & $1: 400$ \\
\hline GATA-4 & Goat & Santa Cruz Biotechnology & sc-69269 & IF & $1: 400$ \\
\hline CYP17 & Mouse & Cell Signaling Technology (Danvers, MA) & 2107 & $\mathrm{IHC}$ & 1:1000 \\
\hline$\beta$-Catenin & Rabbit & Cell Signaling Technology & 9145 & WB & 1:1000 \\
\hline E-cadherin & Rabbit & Cell Signaling Technology & 9134 & WB & 1:1000 \\
\hline $\mathrm{N}$-cadherin & Rabbit & Santa Cruz Biotechnology & sc-7179 & WB & 1:1000 \\
\hline Afadin & Rabbit & Cell Signaling Technology & 9171 & WB & $1: 800$ \\
\hline Vinculin & Rabbit & Cell Signaling Technology & 4441 & WB & 1:1000 \\
\hline GAPDH & Rabbit & Sigma-Aldrich & 3331 & WB & 1:1000 \\
\hline
\end{tabular}

CYP17, 17 $\alpha$-hydroxylase; FAK, focal adhesion kinase; GAPDH, glyceraldehyde 3-phosphate dehydrogenase; GATA, GATA motif binding factor; GGNBP, gametogenetin binding protein; IF, immunofluorescence; IHC, immunohistochemistry; SALL, spalt like transcription factor; SYCP, syanptonemal complex protein; WB, Western blotting. 


\section{Hormone Assays}

Mice were anesthetized and exsanguinated by cardiac puncture. Sera were separated and stored at $-80^{\circ} \mathrm{C}$ until assayed. Luteinizing hormone, follicle-stimulating hormone, and testosterone levels were determined by the Ligand Assay and Analysis Core, Center for Research in Reproduction, the University of Virginia (Charlottesville, VA). Mouse luteinizing hormone was detected by immunoradiometric assays. Radioimmunoassays were used for mouse follicle-stimulating hormone and testosterone measurements. The limits of sensitivities of these assays were $0.07 \mathrm{ng} / \mathrm{mL}$ for luteinizing hormone, $2 \mathrm{ng} / \mathrm{mL}$ for folliclestimulating hormone, and $5 \mathrm{ng} / \mathrm{dL}$ for testosterone.

\section{Stages of Seminiferous Tubule Cycle}

The stages of spermatogenesis were quantitatively evaluated using formalin-fixed, paraffin-embedded testicular sections stained by periodic acid-Schiff. Each stage of seminiferous tubule was determined on the basis of the shape of acrosome of spermatid and overall seminiferous epithelium composition, as described previously, ${ }^{20,21}$ using a bright-field Olympus microscope. The numbers of each stage of tubules in three different cross sections per testis per mouse were counted. A total of three 2-month-old mice in each genotype were analyzed.

The testicular sections were also stained with tetramethylrhodamine-conjugated lectin peanut agglutinin (PNA; Molecular Probes, Waltham, MA) and DAPI (Santa Cruz Biotechnology, Dallas, TX). Each stage (I to XII) of spermatogenesis was identified and imaged with an Olympus fluorescence microscope.

\section{Immunofluorescence Staining}

Testes were fixed in 4\% paraformaldehyde, and embedded in paraffin. Deparaffinized sections were microwaved with 0.1 $\mathrm{mol} / \mathrm{L}$ citrate buffer ( $\mathrm{pH} \mathrm{6.0)}$ for 12 minutes, washed in PBS, blocked with 5\% normal serum containing $0.3 \%$ Triton X-100, and then incubated with primary antibodies, as listed in Table 2 , at $4^{\circ} \mathrm{C}$ overnight. Subsequently, $\alpha$-tubulin was detected by tetramethylrhodamine-conjugated donkey anti-mouse IgG (1:100; Jackson ImmunoResearch Lab, West Grove, PA). Cldauin-11, Spalt-like transcription factor 4, synaptonemal complex protein 3 , and GATA motif binding factor 4 were detected by fluorescein isothiocyanate-conjugated donkey anti-rabbit IgG (1:100; Jackson ImmunoResearch Lab), and acrosomes were stained by tetramethylrhodamine-conjugated lectin PNA in the same slides.

Dispersed spermatogenic cells were prepared by incubation of the seminiferous tubules in PBS supplemented with $0.5 \%$ bovine serum albumin, $2 \mathrm{mg} / \mathrm{mL}$ collagenase, $0.1 \mu \mathrm{g} / \mathrm{mL}$ DNase I, and $0.5 \%$ trypsin (Sigma-Aldrich) for 10 minutes at $33^{\circ} \mathrm{C}$. The cell suspension was filtered through a nylon mesh with $50-\mu \mathrm{m}$ pores. The dissociated cells were then
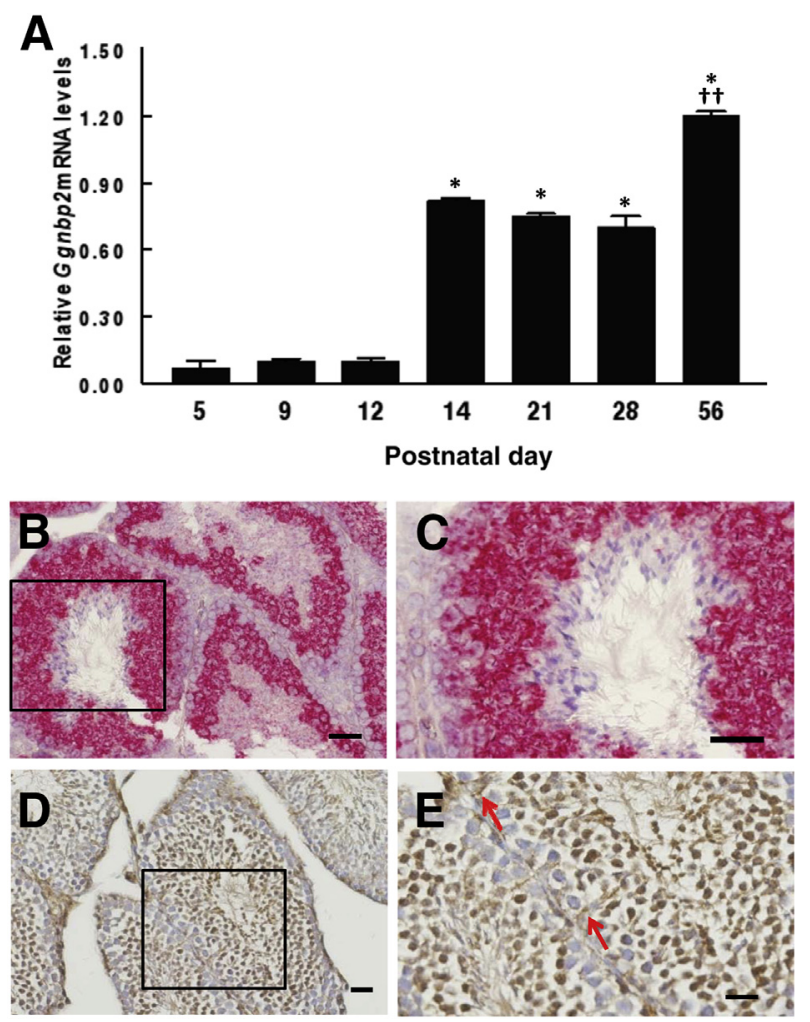

Figure 1 Ggnbp2 mRNA and protein expression in the mouse testes. A: Testicular expression of Ggnbp2 during postnatal development by real-time quantitative PCR analyses. Ggnbp2 mRNA levels are normalized by Gapdh mRNA in each sample. B-E: In situ hybridization (B and C) and immunohistochemistry ( $\mathbf{D}$ and $\mathbf{E}$ ) are performed to determine the localization of Ggnbp2 in 2-month-old testes. Ggnbp2 mRNA (red; B and C) and protein (brown; $\mathbf{D}$ and $\mathbf{E}$ ) are primarily expressed in spermatocytes and spermatids. E: Weak GGNBP2 immunostaining was also observed in Sertoli cells (arrows). The testicular sections are counterstained with hematoxylin. Boxed areas in $\mathbf{B}$ and $\mathbf{D}$ are enlarged in $\mathbf{C}$ and $\mathbf{E}$, respectively. Representative images are from one of three mice examined. Data are expressed as means $\pm \operatorname{SEM}(\mathbf{A}) .{ }^{*} P<0.05$ versus postnatal day $5 ;{ }^{\dagger \dagger} P<0.01$ versus postnatal day 12. Scale bars $=50 \mu \mathrm{m}(\mathbf{B}-\mathbf{E})$.

resuspended in $4 \%$ paraformaldehyde, washed with PBS, spread on slides, and air dried. $\alpha$-tubulin was detected by tetramethylrhodamine-conjugated donkey anti-mouse $\mathrm{IgG}$, and acrosomes were stained by fluorescein isothiocyanate-conjugated lectin PNA in the same slides.

All sections were covered with a DAPI-containing mounting medium to visualize the nuclei. Fluorescent signals on testicular sections were visualized and imaged using an Olympus fluorescence microscope. Replacement of the primary antibody with irrelevant mouse or rabbit $\mathrm{IgG}$ was used as a procedure control.

\section{Biotin Tracer Assay}

The procedure was performed as described by Meng et $\mathrm{al}^{22}$ previously. Two-month-old WT and Ggnbp2KO mice were anesthetized. Testes were exposed by a small incision through the scrotal layer, and $40 \mu \mathrm{L}$ of freshly prepared $10 \mathrm{mg} / \mathrm{mL} \mathrm{EZ-}$ LinkSulfo-NHS-LC-Biotin (Thermo-Fisher Scientific, 

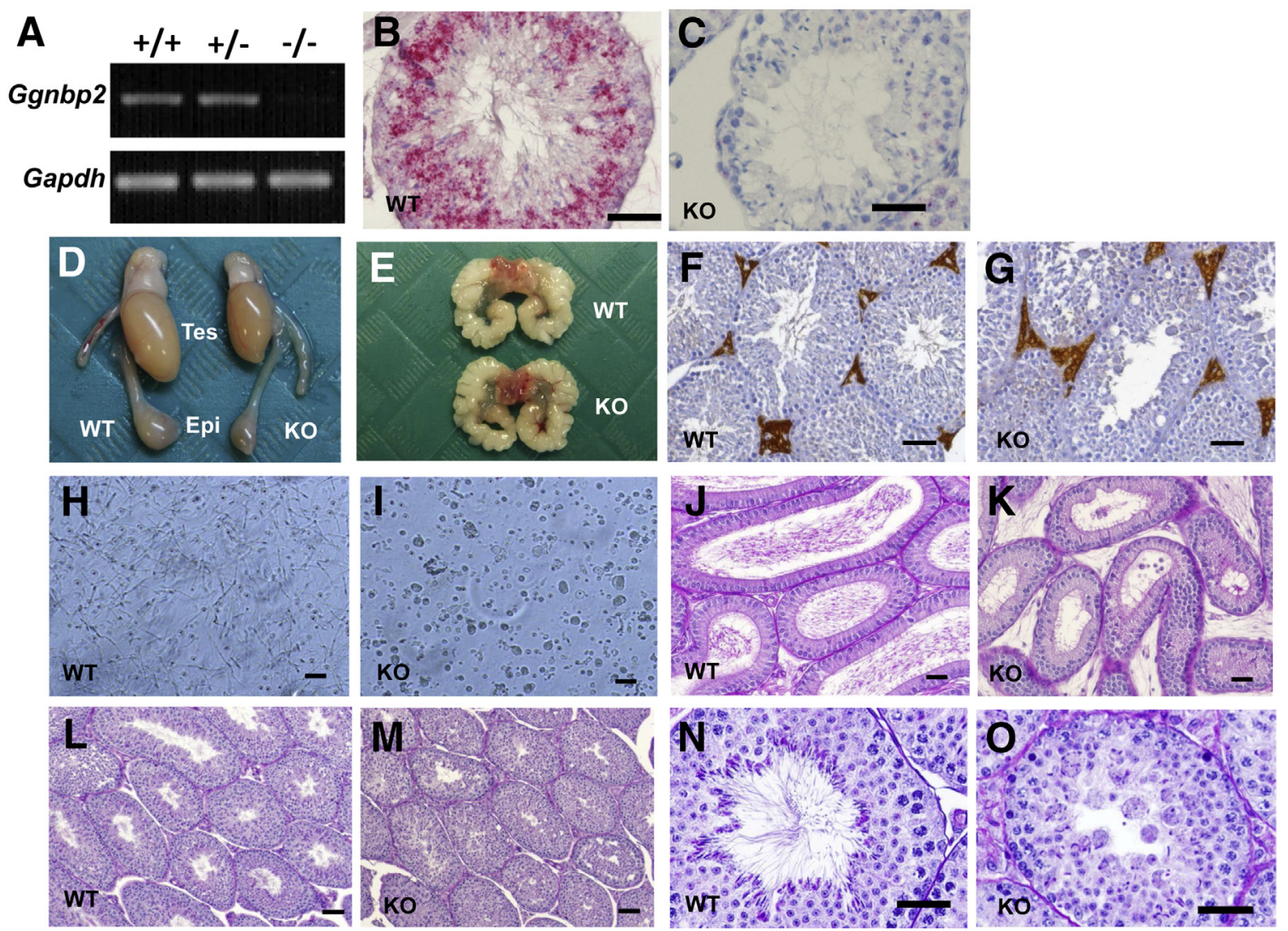

Figure 2 Ggnbp2-null mutation and testicular phenotype. A: RT-PCR analysis of total RNA from 2-month-old adult wild-type (+/+), Ggnbp2KO heterozygous (+/-), and Ggnbp2KO homozygous (-/-) testes shows the absence of Ggnbp2 mRNA in null mutant testes. The housekeeping gene Gapdh serves as an internal control. B and C: In contrast to wild-type (WT; B), in situ hybridization detects no Ggnbp2 mRNA in seminiferous tubules of null mutant testes (K0; C). D and E: Compared to 2-month-old WT mice, the sizes of Ggnbp2-null mutant (KO) testis (Tes) and epididymis (Epi) are noticeably smaller (D), whereas the seminal vesicles are indistinguishable at the same age (E). F and G: Immunohistochemical staining of $17 \alpha$-hydroxylase (a Leydig cell marker) reveals no noticeable difference in the interstitial space between Ggnbp2-null (K0) and WT testes. $\mathbf{H}-\mathrm{K}$ : Phase-contrast (H and I) and periodic acid-Schiff (PAS)-hematoxylinstained ( $\mathbf{J}$ and $\mathbf{K}$ ) images show abundance of mature spermatozoa in 2-month-old WT epididymis ( $\mathbf{H}$ and $\mathbf{J})$, whereas Ggnbp2-null mutant (K0) epididymis contains a few exfoliated germ cells (I and K). L-0: PAS-hematoxylin-stained testicular sections of 2-month-old WT (L and N) and Ggnbp2-null mutant (K0; $\mathbf{M}$ and $\mathbf{0}$ ) mice show that the seminiferous tubules contain disorganized and malformed elongated spermatids. $\mathbf{N}$ and $\mathbf{0}$ : Higher-magnification views of stage $\mathrm{XI}$ seminiferous tubules. Representative images are from one of three WT and three K0 mice that gave similar results. Scale bars $=50 \mu \mathrm{m}(\mathbf{B}-\mathbf{0})$.

Waltham, MA) was gently injected into the interstitium of the testis. Thirty minutes later, the testes were removed and fixed in $10 \%$ formalin and processed for paraffin embedding. The testicular sections were deparaffinized, rehydrated, incubated with $0.02 \mathrm{mg} / \mathrm{mL}$ fluorescein isothiocyanate-conjugated streptavidin (Sigma-Aldrich) at room temperature for $60 \mathrm{mi}-$ nutes, rinsed with PBS, and then mounted with a medium containing DAPI. The slides were examined and imaged with a fluorescence Olympus microscope.

\section{Transmission Electron Microscopy}

Testicular tissues were fixed in 3\% glutaraldehyde and $1.5 \%$ paraformaldehyde (Sigma-Aldrich) for 4 hours at $4^{\circ} \mathrm{C}$. Post-fixation was performed for 1.5 hours at room temperature in $1 \%$ osmium tetroxide and $1.5 \%$ potassium ferrocyanide (Electron Microscopy Sciences, Hatfield, PA). After several rinses in PBS, samples were dehydrated in a graded series of ethanol-acetone and embedded in epoxy resin 618.

Table 3 Effects of Ggnbp2KO on Other Testicular Characteristics of Adult Mice

\begin{tabular}{lccc}
\hline Testicular characteristics & Wild-type mice & Ggnbp2KO mice & $P$ value \\
\hline Ratio of testis/body weight, $g$ & $0.56 \pm 0.1$ & $0.41 \pm 0.07$ & $<0.05(n=10)$ \\
Diameter of seminiferous tubule, $\mu \mathrm{m}$ & $106.6 \pm 0.8$ & $95.1 \pm 0.6$ & $<0.05(n=3)$ \\
Spermatocytes/tubule, $n$ & $62 \pm 11$ & $68 \pm 12$ & $>0.05(n=3)$ \\
Spermatogonia/tubule, $n$ & $4.9 \pm 0.2$ & $4.4 \pm 0.2$ & $>0.05(n=3)$ \\
Sertoli cells/tubule, $n$ & $18.7 \pm 0.2$ & $18 \pm 0.7$ & $>0.05(n=3)$ \\
Apoptotic cells/tubules, $n$ & $5.3 \pm 0.6$ & $5.7 \pm 0.4$ & $>0.05(n=3)$ \\
\hline
\end{tabular}

Data are expressed as means \pm SEM, unless indicated otherwise. 
Table 4 Serum Hormone Levels of Adult Wild-Type and Ggnbp2KO Mice

\begin{tabular}{llrr}
\hline Hormone & Wild-type mice & Ggnbp2KO mice & $P$ value \\
\hline Testosterone, ng/dL & $30.8 \pm 7.45$ & $31.68 \pm 7.72$ & $>0.05$ \\
LH, ng/mL & $0.28 \pm 0.08$ & $0.3 \pm 0.16$ & $>0.05$ \\
FSH, ng/mL & $34.5 \pm 2.01$ & $36.62 \pm 1.78$ & $>0.05$ \\
\hline
\end{tabular}

Data are expressed as means \pm SEM, unless indicated otherwise. $n=10$ in each group.

FSH, follicle-stimulating hormone; LH, luteinizing hormone.

Ultrathin (100 nm thick) sections were then cut, counterstained with uranyl acetate and lead citrate (Electron Microscopy Sciences), and examined and imaged with a Philips EM 208 transmission electron microscope (Philips, Eindhoven, the Netherlands).

\section{Western Blotting}

Western blotting was performed as described previously. ${ }^{10}$ Briefly, the testes of 1-month-old mice were homogenized using a Tissue-Tearor (RPI Corp., Mount Prospect, IL) in a lysis buffer. Protein aliquots were separated in SDS-PAGE gels, transferred to Immobilon-polyvinylidene difluoride membranes (Millipore, Billerica, MA), and then incubated overnight with antibodies, as listed in Table 2. Peroxidaseconjugated secondary antibody (1:2000; Vector Laboratories) was used as the secondary antibody. Immunoblotting signals were detected by the enhanced chemiluminescence Western blotting detection system (GE Healthcare Biosciences, Pittsburgh, PA). All membranes were reblotted with GAPDH antibody as the loading control. The intensity of specific bands was scanned using image analysis software, TotalLab version 2.00 (Nonlinear USA Inc., Durham, NC). The results were presented as the ratio of target protein/GAPDH.

\section{Statistical Analysis}

The data presented are the means \pm SEM. The results were analyzed by one-way analysis of variance and paired $t$-test using a version 17.0 SPSS program (SPSS Inc., Chicago, IL). $P<0.05$ was considered statistically significant.

\section{Results}

Expression and Localization of Ggnbp2 in the Postnatal Mouse Testes

To determine the expression of Ggnbp2 during postnatal development, real-time quantitative RT-PCR was performed to analyze RNA isolated from mouse testes at postnatal days $5,9,12,14,21,28$, and 56. Low levels of Ggnbp2 mRNA were detected in the testes of 5- to 12-day-old mice
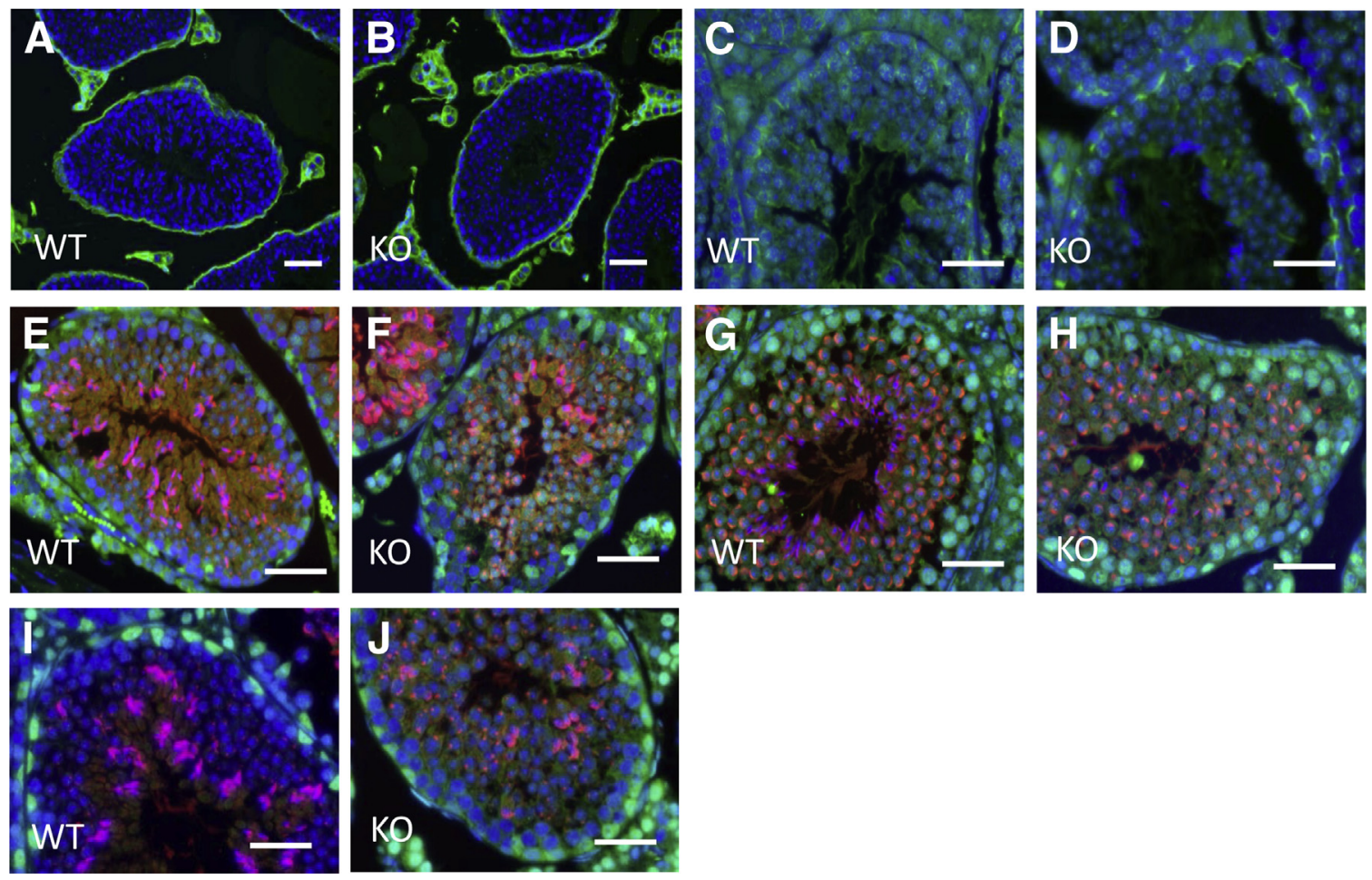

Figure 3 The integrity of the blood-testis barrier $(\mathbf{A}-\mathbf{D})$, spermatogonia ( $\mathbf{E}$ and $\mathbf{F})$, spermatocytes $(\mathbf{G}$ and $\mathbf{H})$, and Sertoli cells ( $\mathbf{I}$ and $\mathbf{J})$ in the seminiferous tubules of 2-month-old wild-type (WT) and Ggnbp2-null mutant (KO) testes. A and B: No biotin tracer (green) was observed in the lumen in either WT or KO seminiferous tubules. C-J: Immunofluorescence staining (green) of claudin-11 (a tight junction protein; C and D), SALL4 (a spermatogonial marker; E and F), synaptonemal complex protein 3 (a spermatocyte marker; $\mathbf{G}$ and $\mathbf{H}$ ), and GATA motif binding factor 4 (a Sertoli cell marker; I and $\mathbf{J}$ ) does not reveal any differences between WT and KO testes. The cell nuclei are stained by DAPI (blue). Also costaining with peanut agglutinin-lectin (red; E-J). Representative images are from one of three WT and three $\mathrm{KO}$ mice that gave similar results. Scale bars $=50 \mu \mathrm{m}(\mathbf{A}-\mathbf{J})$. 

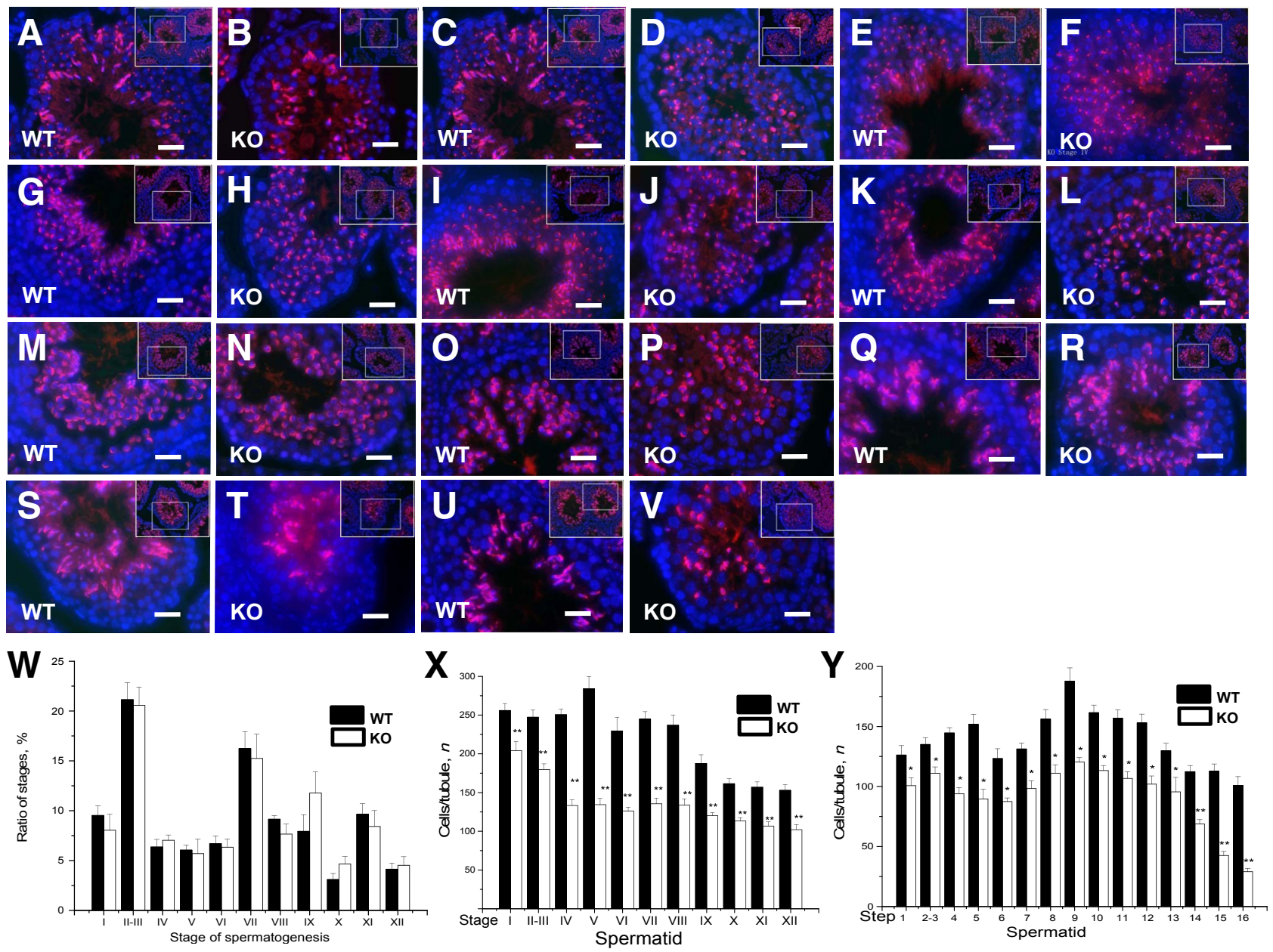

Figure 4 Analyses of spermatogenetic stages of 2-month-old wild-type (WT) and Ggnbp2-null mutant (K0) testes. A-V: Fluorescent images of peanut agglutinin-lectin (red) and DAPI (blue) stained seminiferous epithelium enlarged from boxed areas of lower-magnification micrograph (insets) display different stages of spermatogenesis (I to XII) of WT and KO testes. A and B: Stage I. C and D: Stage II to III. E and F: Stage IV. G and H: Stage V. I and J: Stage VI. K and L: Stage VII. M and N: Stage VIII. $\mathbf{O}$ and P: Stage IX. Q and R: Stage X. S and T: Stage XI. U and V: Stage XII. W: The proportion of the stage of seminiferous epithelium in WT and $\mathrm{KO}$ testes shows no significant difference. $\mathbf{X}$ and $\mathbf{Y}$ : The numbers of spermatids at different stages (I to XII) of seminiferous tubules (X) and the developmental steps (1 to 16) of spermatids per tubules (Y) are significantly reduced in Ggnbp2KO mice. Representative images are from one of three WT and three KO mice that gave similar results. Data are expressed as means \pm SEM. ${ }^{*} P<0.05,{ }^{*} P<0.01$ versus WT. Scale bars $=50 \mu \mathrm{m}(\mathbf{A}-\mathbf{V})$.

(Figure 1A). The expression significantly increased from postnatal day 14 and remained constant in juvenile mice. The highest levels were found in sex mature adults (Figure 1A).

The localization of Ggnbp2 mRNA and its protein in the adult mouse testes was examined by mRNA in situ hybridization (Figure 1, B and C) and immunohistochemical staining (Figure 1, D and E). The results showed that Ggnbp 2 mRNA was primarily expressed in spermatocytes and spermatids in seminiferous tubules. A weak expression was seen in Sertoli cells but not in spermatozoa and interstitial Leydig cells. The control probe $\operatorname{dap} B$ did not detect any signals above the background levels (data not shown). Although no Ggnbp2 mRNA hybridization signal was found in spermatozoa (Figure 1C), immunohistochemistry showed that GGNBP2 presented not only in spermatocytes and spermatids but also in spermatozoa. Moreover, the immunostaining is observed in the nuclei of spermatids and spermatozoa (Figure 1E). Compared to the adult testis, intermediate levels of Ggnbp2 mRNA and protein were also seen in the adult mouse ovarian tissues (data not shown).

\section{Ggnbp2-Null Mutation Results in an Azoospermic Phenotype}

Ggnbp2KO heterozygous mice on a C57BL/6 background were generated in our laboratory previously. Ggnbp2-null mutant fetuses died in utero because of a defective placenta. ${ }^{10}$ In this study, we established Ggnbp $2 \mathrm{KO}$ heterozygous colonies on a mixed C57BL/6/129 background. By breeding this mixed background of Ggnbp $2 \mathrm{KO}$ heterozygous mice, $6.8 \%$ instead of $25 \%$ (the mendelian ratio) of Ggnbp2-null mutant males and females were born alive and grew to adulthood. There were no Ggnbp2 transcripts detectable in 2-month-old null mutant testes by RT-PCR 

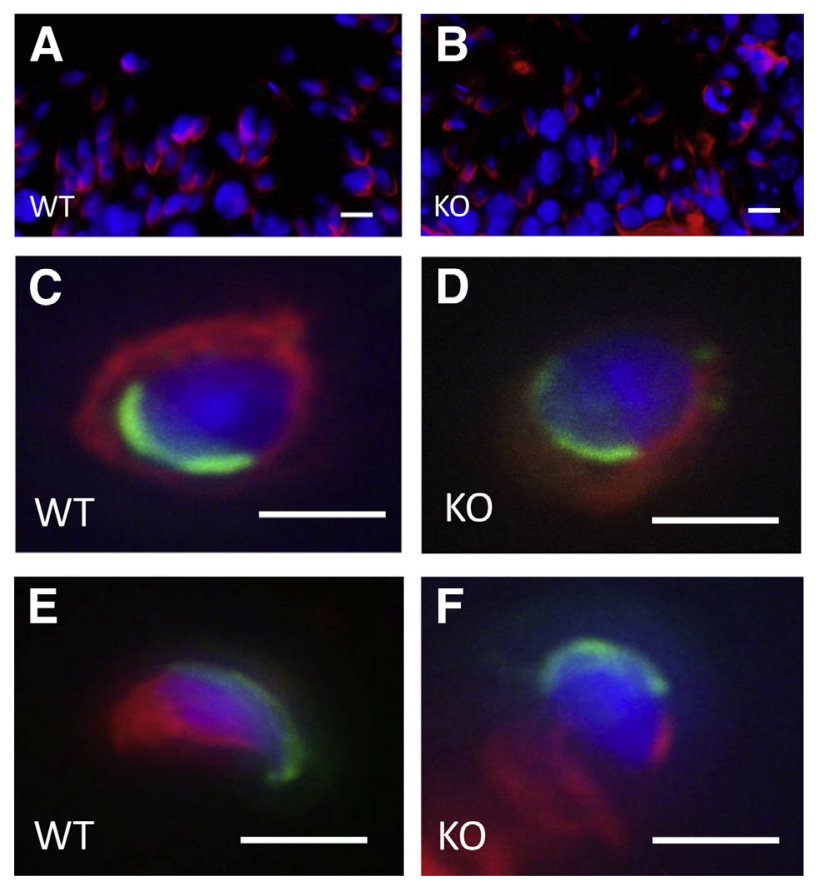

Figure 5 Immunofluorescence staining of manchette by $\alpha$-tubulin (red) of 2-month-old wild-type (WT) and Ggnbp2-null mutant (K0) testicular sections ( $\mathbf{A}$ and $\mathbf{B})$ and dispersed elongating spermatids $(\mathbf{C}-\mathbf{F})$. The nuclei of spermatogenic cells are stained by DAPI (blue), and the acrosomes of dispersed spermatids are stained by peanut agglutinin-lectin (green; C-F). B: Dislocated and dispersed $\alpha$-tubulin staining in the null mutant testicular seminiferous epithelium is observed. $\mathbf{D}$ and $\mathbf{F}$ : The microtubule bundles of the manchette skirt in null mutant elongating spermatids are unevenly distributed, with a shaggy appearance and distorted acrosomes. Representative images are from one of three WT and three K0 mice that gave similar results. Scale bars $=20 \mu \mathrm{m}(\mathbf{A}-\mathbf{F})$.

(Figure 2) and in situ hybridization (Figure 2). Ggnbp2-null mutant mice appeared to be healthy, with normal extragenital development and sexual behavior. However, despite repeated mating with proven fertile females for 6 months, Ggnbp2-null mutant males did not sire any offspring (data not shown). In contrast to males, null mutant females produce progeny normally, indicating that deletion of Ggnbp2 that led to infertility is sex specific.

Although the seminal vesicles of Ggnbp2-null mutant males were developed well, the size of testes of 2-month-old mice were smaller than those of WT siblings (Figure 2) and testicular weight was significantly reduced (Table 3 ). Interestingly, serum luteinizing hormone, follicle-stimulating hormone, and testosterone levels were not statistically different from WT siblings (Table 4). Moreover, no noticeable difference in interstitial space of the seminiferous tubules was noticed between null mutant (Figure 2) and WT (Figure 2) testes, as revealed by immunostaining of a Leydig cell marker, $17 \alpha$-hydroxylase (Figure 2). This suggests that reduced testicular size is not attributable to the endocrine dysfunction of the hypothalamus-pituitary-gonadal axis in Ggnbp2-null mutant mice.

Light microscopic analyses of the epididymis and testes revealed no spermatozoa presence in either organ of 2-month-old Ggnbp2-null mice (Figure 2). The lumens of epididymal ducts of Ggnbp2-null mice only contained a few sloughed germ cells (Figure 2). In contrast, the lumens of epididymal ducts from WT siblings filled with mature spermatozoa (Figure 2). The diameters of the seminiferous tubules were significantly reduced in 2-month-old null mutant testes (Table 3). There was no obvious difference in histological appearances in 1-month-old testes between WT and null mutants (data not shown). The seminiferous epithelium in 2-month-old Ggnbp2-null testes consisted of spermatogonia, spermatocytes, round spermatids, and Sertoli cells. Although elongated spermatids were present, they were disorganized, with deformed nuclei. The lumens of the seminiferous tubules contained sloughed late steps of abnormal spermatids (Figure 2). Together, these data indicate that disruption of Ggnbp2 results in an azoospermic phenotype.

To test whether the integrity of the blood-testis barrier was impaired in Ggnbp2-null testes, surface biotinylated tracer was injected into the testicular interstitium. In both WT and null mutant testes, biotin tracer was limited to the testicular interstitium and the basal compartment of the seminiferous tubules. No biotin tracer was detected in the lumens of the seminiferous tubules (Figure 3, A and B). These results suggest that defective spermatogenesis in Ggnbp2-null mutant testes is not associated with an impaired blood-testis barrier. Consistent with this interpretation, a blood-testis barrier tight junction component, claudin-11 immunofluorescence staining, showed no difference in the tubular basal compartment in WT and null mutant testes (Figure 3, C and D).

\section{Defective Spermiogenesis Leads to Azoospermia in the Absence of Ggnbp2}

By examining cross sections of the seminiferous tubules of 2-month-old testes stained with Spalt-like transcription factor 4 (a spermatogonial marker) (Figure 3, E and F), synaptonemal complex protein 3 (a spermatocyte marker) (Figure 3, G and H), and GATA motif binding factor 4 (a Sertoli cell marker) (Figure 3, I and J) and quantitatively analyzing the numbers, the results showed that the mean numbers of spermatogonia, spermatocytes, and Sertoli cells per cross section of the seminiferous tubule were not significantly different between Ggnbp2-null mutants and WT siblings (Table 3 ). In addition to the observation of spermatogonia, spermatocytes, and Sertoli cells in the seminiferous tubules, staging analyses of cross sections of the seminiferous tubules were performed in periodic acid-Schiff-hematoxylin- and lectin-PNA-stained 2month-old WT and Ggnbp2-null testes using the staging criteria described by Russell et $\mathrm{al}^{20}$ and Nakata et al. ${ }^{21}$ Twelve stages of lectin-PNA-stained cross sections of the seminiferous tubules of WT and Ggnbp2-null testes were presented in Figure 4. Quantitative data demonstrated that Ggnbp2-null mutants have a complete continuous 

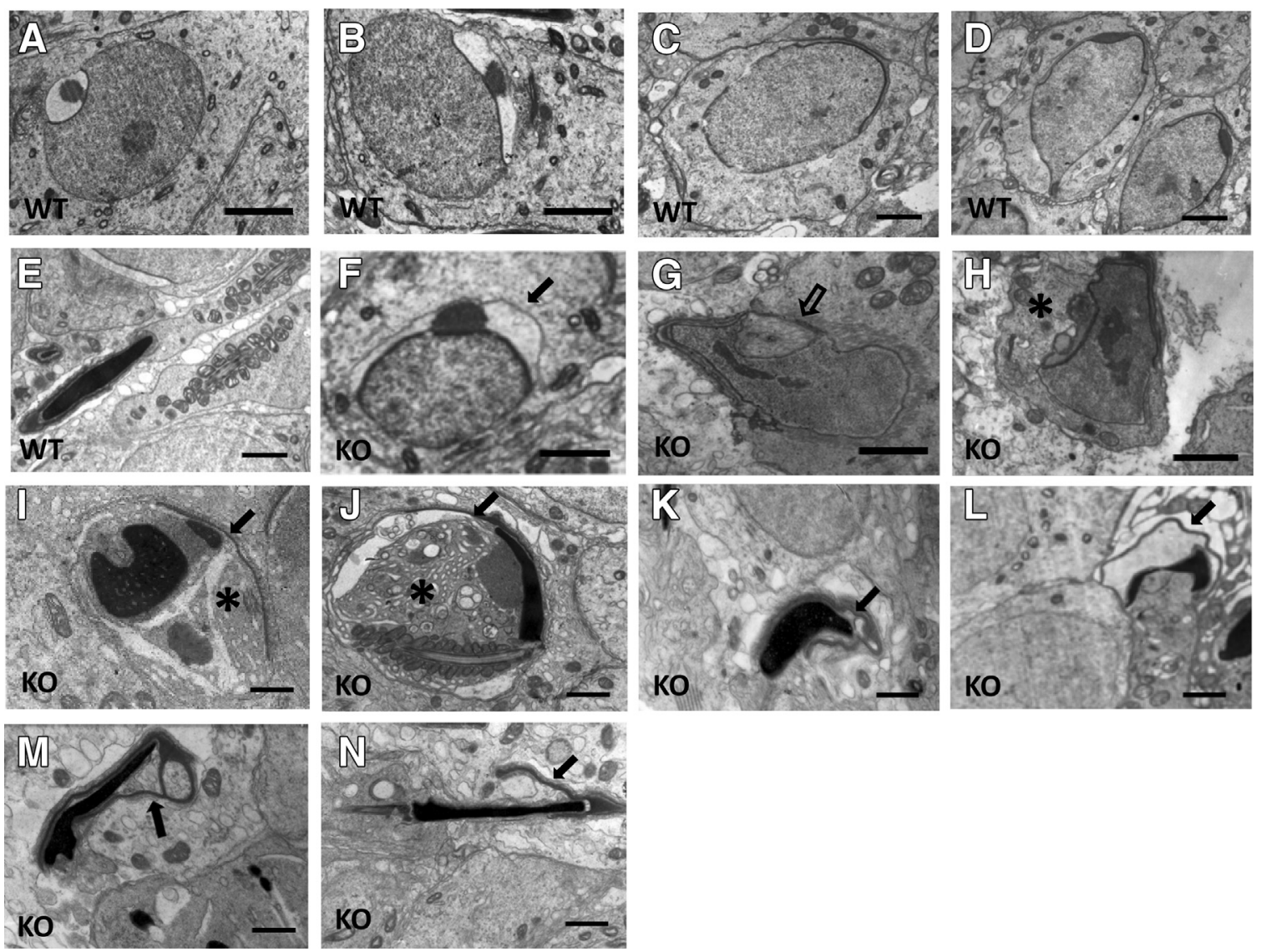

Figure 6 Ultrastructural abnormalities of spermatids in the Ggnbp2-null testes. Transmission electron microscopic images show elongating (A-D) and elongated (E) spermatids in 2-month-old wild-type (WT) testes. In the absence of Ggnbp2 (K0), the mutant elongating (F-H) and elongated (I-N) spermatids frequently contain ill-formed nuclei, cytoplasmic remnant (asterisks), ectopic manchette (open arrow), and distorted or detached acrosomes (closed arrows). Scale bars $=1 \mu \mathrm{m}(\mathbf{A}-\mathbf{N})$.

process of spermatogenesis, similar to WT siblings (Figure 4). However, there was a marked decline in quantity of spermatids in each stage of the seminiferous tubules in the null mutant mice (Figure 4). On the basis of the morphology of the acrosome formation and shape of spermatids, as described by Russell et $\mathrm{al}^{20}$ and Nakata et $\mathrm{al}^{21} 16$ steps of spermatid development were analyzed. As shown in Figure 4, the spermatid numbers per tubule between WT and Ggnbp2-null mutants were noticeably lower in the null mutant testes than WT siblings. A more dramatic decrease was observed at later steps of spermatid development. These observations indicate that defective spermiogenesis leads to azoospermia in the absence of Ggnbp2 in the testis.

\section{Loss of Ggnbp2 Causes Abnormal Transformation of Spermatids}

Immunofluorescence analysis using $\alpha$-tubulin as a microtubule marker revealed that Ggnbp2-null spermatids contained abnormal manchette. Unlike WT spermatids, normal bell-shaped manchettes covering typical ovoid-shaped nuclei in elongating spermatids (Figure 5A), the manchette lost its special perinuclear symmetrical distribution in most spermatids (Figure 5B). Dislocated and dispersed $\alpha$-tubulin staining, with misshapen spermatid nuclei, was observed. Costaining of $\alpha$-tubulin and acrosome by lectin-PNA showed that the microtubule bundles of the manchette skirt were unevenly distributed, with a shaggy appearance and distorted acrosomes (Figure 5, D and F) compared to WT cells (Figure 5, C and E).

Transmission electron microscopic analyses of testes of 2-month-old Ggnbp2-null mutant mice were performed to further interrogate the pathological changes of spermatid development. Ultrastructural evidence revealed dramatic morphological defects of developing spermatids in the Ggnbp2-null testes, including irregularly shaped acrosomes, acrosome detachment, cytoplasmic remnant, ectopic manchette, and ill-formed bizarre head shape in both elongating and elongated spermatids (Figure 6, F-N). In contrast, normal acrosome, nucleus, and manchette were found in a well-organized arrangement in WT testes (Figure 6, A-E).

\section{Altered Adhesion Protein Expression in 1-Month-0ld Ggnbp2-Null Testes}

Pronounced spermatid deformation in the Ggnbp2-null testes prompted us to investigate whether Ggnbp2 ablation 


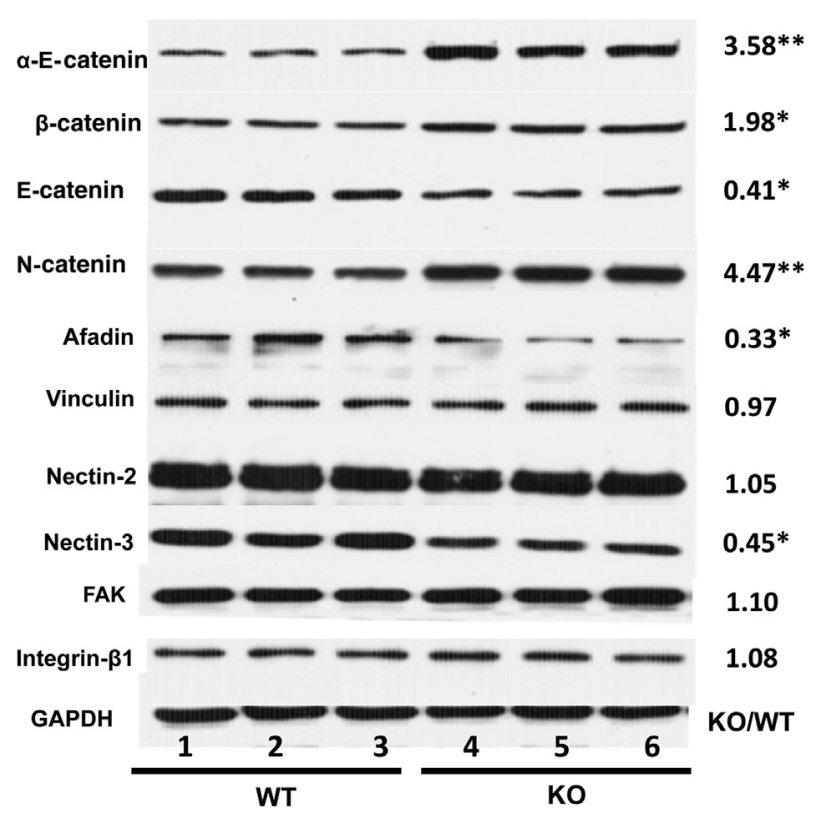

Figure 7 Altered adhesion protein expression in 1-month-old Ggnbp2null testes. Western blot results show that the protein levels of $\alpha$-E-catenin, $\beta$-catenin, and $\mathrm{N}$-cadherin are significantly elevated, $\mathrm{E}$-cadherin, afadin, and nectin-3 are markedly reduced, and vinculin, nectin-2, focal adhesion kinase (FAK), and integrin- $\beta 1$ are not changed in Ggnbp2-deficient testes compared to wild type (WT). Representative images of three WT (1 to 3 ) and knockout (K0; 4 to 6 ) mice are shown. ${ }^{*} P<0.05,{ }^{*} P<0.01$ versus WT. $\mathrm{GAPDH}$, glyceraldehyde 3-phosphate dehydrogenase.

had an impact on the interactions of spermatids and Sertoli cells in the adluminal compartment. Western blots were performed to examine a range of adhesion and associated protein levels in 1-month-old testes. The reason for examining 1-month-old testes was that round spermatids have been formed and spermiogenesis begins by this time, whereas the testes were morphologically comparable between WT and Ggnbp2-null mutants at this age. The results showed that $\alpha$-E-catenin, $\beta$-catenin, and $\mathrm{N}$-cadherin increased, E-cadherin, afadin, and nectin-3 decreased, and vinculin, nectin-2, focal adhesion kinase, and integrin- $\beta 1$ were unchanged in Ggnbp2-null testes compared to WT siblings (Figure 7).

\section{Discussion}

In this report, we demonstrated that GGNBP2 is an important regulator of spermatid differentiation in mice. Our laboratory previously reported that Ggnbp2-null mutant on a C57BL/6 background was embryonic lethal. ${ }^{10}$ Chen et $\mathrm{al}^{23}$ recently reported that only three null mutant males (4 of 179) were viable on the B6 background, and they were infertile, suggesting that most Ggnbp2-null fetuses die in utero. On a mixed B6/129 genetic background, $6.8 \%$ of viable Ggnbp2-null mutant mice are obtained, suggesting an incompletely penetrant phenotype. Interestingly, a recent high-throughput study of 1751 unique gene knockouts in mice reveals that incomplete penetrance and variable expressivity are common, even on a defined genetic background. $^{24}$

Histological examination reveals that the most dramatic impact of the loss of Ggnbp2 causes failure of round spermatids from developing into elongated spermatids. As a result, there was complete lack of mature spermatozoa. Ultrastructural analysis shows the presence of multiple malformed elongating and elongated spermatids. Improper formation and detachment of the acrosomes, misshapen nuclei, abnormal tails, ectopic manchettes, and cytoplasmic retention all point to a failure to proceed through the complicated spermiogenic process.

Cells of the seminiferous adluminal compartment are located between elongating/elongated spermatids and Sertoli cells and anchor the spermatids until they complete their differentiation. Several adhesion and associated proteins, such as nectin/afadin, cadherin/catenin, and $\beta-1$ integrin/focal adhesion kinase/vinculin, are known to constitute anchoring junction complexes and are crucial for normal spermiogenesis. ${ }^{25-28}$ For example, nectin-2 is known to bind to nectin-3 heterotypically in the plasma membrane of spermatid-Sertoli cells. ${ }^{29,30}$ Alteration of the nectin-2/nectin-3 ratio results in aberrant morphogenesis and positioning of spermatids. ${ }^{31-34}$ In the Ggnbp2null testes, we observed that disfigured spermatids are populated in disorganized seminiferous adluminal epithelium. The seminiferous lumen contains spermatids, likely being sloughed off seminiferous epithelium prematurely. Western blot analyses show that several adhesion and associated protein expression levels in the testes are altered in the absence of Ggnbp2, which include increased $\alpha$-E-catenin, $\beta$-catenin, and $\mathrm{N}$-cadherin and decreased afadin, $\mathrm{N}$-cadherin, and nectin-2 protein levels. These data suggest that dysregulation of these adhesion proteins and associated molecules caused by Ggnbp 2 deletion may lead to an imbalance of these anchoring junction complexes and perturb the interactions among spermatidspermatid and spermatid-Sertoli cells that eventually contribute to the failure of spermatid morphogenesis and differentiation. In this context, future detailed studies of the adhesion and associated protein recycling and turnover in the WT and Ggnbp2KO testes, as spermatids differentiate to spermatozoa, should provide a better understanding of GGNBP2-regulated processes during spermatogenesis.

Ggnbp2 is predominately expressed germ cells coinciding with the appearance of spermatocytes during postnatal development. The adhesion and associated proteins that are mainly in Sertoli cells, such as nectin-2, vinculin, integrin- $\beta 1$, and focal adhesion kinase, ${ }^{29,30,35,36}$ are not significantly altered by Ggnbp 2 deletion. Moreover, using GATA motif binding factor 4 as a Sertoli cell maker, the number of GATA motif binding factor 4-positive cells appears to be comparable to WT testes. Although the abnormalities of spermatid transformation 
observed in Ggnbp2-null mutant testes appears to arise from defects in germ cells, we could not completely exclude the possibility of malfunctioned Sertoli cells. Recently, Chen et al ${ }^{23}$ reported that sex-determining region Y-box 9 was not detectable by immunofluorescence staining in adult Ggnbp2-null testes. SOX9 is known to be necessary for testicular development and Sertoli cell differentiation. ${ }^{37}$ Therefore, further studies of selective Sertoli and germ cell Ggnbp2 knockout in vivo as well as Sertoli-Sertoli and Sertoli-germ cell interactions in vitro should provide a better understanding of the biochemical and cell biological roles of GGNBP2 in regulation of spermiogenesis.

It is likely that a lack of GGNBP2 in germ cells disrupts the integrity of the seminiferous epithelium, which consequently causes defective spermatid differentiation. There is evidence showing that GGNBP2 physically interacts with GGN. GGN is a germ cell-specific protein highly expressed in the testes. ${ }^{13,38}$ Complete deletion of $G g n$ leads to embryonic lethality before implantation. Haploinsufficiency of Ggn in mouse pachytene spermatocytes results in an increased incidence of unrepaired DNA doublestrand breaks. ${ }^{39}$ Whether GGNBP2 may affect germ cell meiosis through the interaction with GGN is warranted for further studies.

A spermiogenesis defect is one of the common causes of male infertility in humans, but the etiology is not completely understood. ${ }^{6,40,41}$ Highly conserved GGNBP2 between mice and humans ${ }^{10}$ and the specific loss of GGNBP2 function that leads to spermiogenic failure in mice raise the possibility that GGNBP2 may have a similar role in human spermiogenesis. Thus, the Ggnbp2KO mouse model provides a basis for further studies to explore the biological processes that are regulated by this protein during the spermiogenic stage of spermatogenesis, and to help us understand the molecular defects that are associated with male infertility. Moreover, Ggnbp2KO leads to male-specific infertility without affecting the hypothalamus-pituitary-gonadal axis. The integrity of testicular blood-testis barrier and the numbers of spermatogonia, spermatocytes, and Sertoli cells appear to be unaffected. A selective effect of GGNBP2 on haploid spermatid differentiation without disturbance of the entire spermatogenic processes makes GGNBP2 a candidate for future development of a male nonhormonal contraceptive target.

In summary, we discover that GGNBP2, possibly through its role in regulation of adlumenal integrity of germ epithelium, is essential for spermiogenesis. However, the molecular actions of GGNBP2 in the testis remain unclear. Further studies will help us gain more insight into the genetic regulation of spermatogenesis.

\section{Acknowledgment}

We thank Robin J. Lawrence for helpful advice in the preparation and editing of the manuscript.

\section{References}

1. Eddy EM: The spermatozoon. Knobil and Neill's Physiology of Reproduction, ed 3. Edited by Neill JD. San Diego: Academic Press, 2006. pp. $3-54$

2. Hess RA, Renato de Franca L: Spermatogenesis and cycle of the seminiferous epithelium. Adv Exp Med Biol 2008, 636:1-15

3. Schultz N, Hamra FK, Garbers DL: A multitude of genes expressed solely in meiotic or postmeiotic spermatogenic cells offers a myriad of contraceptive targets. Proc Natl Acad Sci U S A 2003, 100: 12201-12206

4. Zheng H, Stratton CJ, Morozumi K, Jin J, Yanagimachi R, Yan W: Lack of Spem1 causes aberrant cytoplasm removal, sperm deformation, and male infertility. Proc Natl Acad Sci U S A 2007, 104:6852-6857

5. Yan W: Male infertility caused by spermiogenic defects: lessons from gene knockouts. Mol Cell Endocrinol 2009, 306:24-32

6. Chen SR, Batool A, Wang YQ, Hao XX, Chang CS, Cheng CY, Liu YX: The control of male fertility by spermatid-specific factors: searching for contraceptive targets from spermatozoon's head to tail. Cell Death Dis 2016, 7:e2472

7. Ohbayashi T, Oikawa K, Iwata R, Kameta A, Evine K, Isobe T, Matsuda Y, Mimura J, Fujii-Kuriyama Y, Kuroda M, Mukai K: Dioxin induces a novel nuclear factor, DIF-3, that is implicated in spermatogenesis. FEBS Lett 2001, 508:341-344

8. Zhang J, Wang Y, Zhou Y, Cao Z, Huang P, Lu B: Yeast two-hybrid screens imply that GGNBP1, GGNBP2 and OAZ3 are potential interaction partners of testicular germ cell-specific protein GGN1. FEBS Lett 2005, 579:559-566

9. Duan CJ, Jiang TB, Li C: [Screening the effective target sequences of laryngeal carcinoma related gene LCRG1] Chinese. Zhong Nan Da Xue Xue Bao Yi Xue Ban 2008, 33:468-475

10. Li S, Moore AK, Zhu J, Li X, Zhou H, Lin J, He Y, Xing F, Pan Y, Bohler HC, Ding J, Cooney AJ, Lan Z, Lei Z: Ggnbp2 is essential for pregnancy success via regulation of mouse trophoblast stem cell proliferation and differentiation. Biol Reprod 2016, 94:41

11. Li YJ, Xie HL, Chen ZC, He CM: Cloning and expression analysis of a laryngeal carcinoma related gene, LCRG1. Sheng Wu Hua Xue Yu Sheng Wu Wu Li Xue Bao (Shanghai) 2001, 33:315-319

12. Li Y, Chen Z: Molecular cloning and characterization of LCRG1 a novel gene localized to the tumor suppressor locus D17S800D17S930. Cancer Lett 2004, 209:75-85

13. Zhang X, Xiao Z, Chen Z, Li C, Li J, Yanhui Y, Yang F, Yang Y, Oyang Y: Comparative proteomics analysis of the proteins associated with laryngeal carcinoma-related gene 1. Laryngoscope 2006, 116:224-230

14. Yin F, Liu L, Liu X, Li G, Zheng L, Li D, Wang Q, Zhang W, Li L: Downregulation of tumor suppressor gene ribonuclease T2 and gametogenetin binding protein 2 is associated with drug resistance in ovarian cancer. Oncol Rep 2014, 32:362-372

15. Guan R, Hou DF, Rao X, Guan YJ, Ouyang YM, Yu YH, Jim H, Chen ZC: ZNF403, a novel cell cycle regulator. Prog Biochem Biophys $2013,40: 147-158$

16. Wu Y, Hu X, Li Z, Wang M, Li S, Wang X, Lin X, Liao S, Zhang Z, Feng X, Wang S, Cui X, Wang Y, Gao F, Hess RA, Han C: Transcription factor RFX2 is a key regulator of mouse spermiogenesis. Sci Rep 2016, 6:20435

17. Clark AT, Firozi K, Justice MJ: Mutations in a novel locus on mouse chromosome 11 resulting in male infertility associated with defects in microtubule assembly and sperm tail function. Biol Reprod 2004, 70: $1317-1324$

18. Lan ZJ, Krause MS, Redding SD, Li X, Wu GZ, Zhou HX, Bohler HC Ko C, Cooney AJ, Zhou J, Lei ZM: Selective deletion of Pten in thecainterstitial cells leads to androgen excess and ovarian dysfunction in mice. Mol Cell Endocrinol 2017, 444:26-37

19. Livak KJ, Schmittgen TD: Analysis of relative gene expression data using real-time quantitative PCR and the 2(-Delta Delta C(T)) Method. Methods 2001, 25:402-408 
20. Russell LD, Ettlin RA, Sinkim Hikim AP, Clegg ED: Staging for laboratory species. Histological and Histopathological Evaluation of the Testis, ed 1. Clearwater, FL: Cache River Press, 1990. pp. 62-193

21. Nakata H, Wakayama T, Takai Y, Iseki S: Quantitative analysis of the cellular composition in seminiferous tubules in normal and genetically modified infertile mice. J Histochem Cytochem 2015, 63 : 99-113

22. Meng J, Holdcraft RW, Shima JE, Griswold MD, Braun RE: Androgens regulate the permeability of the blood-testis barrier. Proc Natl Acad Sci U S A 2005, 102:16696-16700

23. Chen A, Li J, Song L, Ji C, Boing M, Chen J, Brand-Saberi B: GGNBP2 is necessary for testis morphology and sperm development. Sci Rep 2017, 7:2998

24. Dickinson ME, Flenniken AM, Ji X, Teboul L, Wong MD, White JK, et al: High-throughput discovery of novel developmental phenotypes. Nature 2016, 537:508-514

25. Goossens S, van Roy F: Cadherin-mediated cell-cell adhesion in the testis. Front Biosci 2005, 10:398-419

26. Lui WY, Lee WM: Mechanisms of reorganization of cell-cell junctions in the testis. Front Biosci 2008, 13:6775-6786

27. Cheng CY, Mruk DD: A local autocrine axis in the testes that regulates spermatogenesis. Nat Rev Endocrinol 2010, 6:380-395

28. Upadhyay RD, Kumar AV, Ganeshan M, Balasinor NH: Tubulobulbar complex: cytoskeletal remodeling to release spermatozoa. Reprod Biol Endocrinol 2012, 10:27

29. Huang K, Lui WY: Nectins and nectin-like molecules (Necls): recent findings and their role and regulation in spermatogenesis. Semin Cell Dev Biol 2016, 59:54-61

30. Ozaki-Kuroda K, Nakanishi H, Ohta H, Tanaka H, Kurihara H, Mueller S, Irie K, Ikeda W, Sakai T, Wimmer E, Nishimune Y, Takai Y: Nectin couples cell-cell adhesion and the actin scaffold at heterotypic testicular junctions. Curr Biol 2002, 12:1145-1150

31. Bouchard MJ, Dong Y, McDermott BM Jr, Lam DH, Brown KR, Shelanski M, Bellve AR, Racaniello VR: Defects in nuclear and cytoskeletal morphology and mitochondrial localization in spermatozoa of mice lacking nectin-2, a component of cell-cell adherens junctions. Mol Cell Biol 2000, 20:2865-2873
32. Toyama Y, Suzuki-Toyota F, Maekawa M, Ito C, Toshimori K: Disruption of ectoplasmic specializations between Sertoli cells and maturing spermatids by anti-nectin-2 and anti-nectin-3 antibodies. Asian J Androl 2008, 10:577-584

33. Mueller S, Rosenquist TA, Takai Y, Bronson RA, Wimmer E: Loss of nectin-2 at Sertoli-spermatid junctions leads to male infertility and correlates with severe spermatozoan head and midpiece malformation, impaired binding to the zona pellucida, and oocyte penetration. Biol Reprod 2003, 69:1330-1340

34. Inagaki $\mathrm{M}$, Irie $\mathrm{K}$, Ishizaki $\mathrm{H}$, Tanaka-Okamoto $\mathrm{M}$, Miyoshi $\mathrm{J}$, Takai Y: Role of cell adhesion molecule nectin-3 in spermatid development. Genes Cells 2006, 11:1125-1132

35. Grove BD, Pfeiffer DC, Allen S, Vogl AW: Immunofluorescence localization of vinculin in ectoplasmic ("junctional") specializations of rat Sertoli cells. Am J Anat 1990, 188:44-56

36. Wong $\mathrm{CH}$, Cheng $\mathrm{CY}$ : Mitogen-activated protein kinases, adherens junction dynamics, and spermatogenesis: a review of recent data. Dev Biol 2005, 286:1-15

37. Moniot B, Declosmenil F, Barrionuevo F, Scherer G, Aritake K, Malki S, Marzi L, Cohen-Solal A, Georg I, Klattig J, Englert C, Kim Y, Capel B, Eguchi N, Urade Y, Boizet-Bonhoure B, Poulat F: The PGD2 pathway, independently of FGF9, amplifies SOX9 activity in Sertoli cells during male sexual differentiation. Development 2009, 136:1813-1821

38. Zhao Q, Zhou Y, Cao Z, Zhu H, Huang P, Lu B: Germ-cell specific protein gametogenetin protein 2 (GGN2), expression in the testis, and association with intracellular membrane. Mol Reprod Dev 2005, 72: $31-39$

39. Jamsai D, O'Connor AE, Deboer KD, Clark BJ, Smith SJ, Browne CM, Bensley JG, Merriman JA, Yuen WS, Koopman P, Jones KT, O'Bryan MK: Loss of GGN leads to pre-implantation embryonic lethality and compromised male meiotic DNA double strand break repair in the mouse. PLoS One 2013, 8:e56955

40. Yan W, Ma L, Burns KH, Matzuk MM: Haploinsufficiency of kelchlike protein homolog 10 causes infertility in male mice. Proc Natl Acad Sci U S A 2004, 101:7793-7798

41. O'Donnell L: Mechanisms of spermiogenesis and spermiation and how they are disturbed. Spermatogenesis 2014, 4:e979623 